\title{
Effect of Formulation Factors on In Vitro Transcorneal Permeation of Gatifloxacin From Aqueous Drops
}

Submitted: December 16, 2005; Accepted: April 21, 2006; Published: July 7, 2006

Mahendra Singh Rathore ${ }^{1}$ and Dipak K. Majumdar ${ }^{1}$

${ }^{1}$ Department of Pharmaceutics, Delhi Institute of Pharmaceutical Sciences and Research, formerly College of Pharmacy, University of Delhi, Pushp Vihar, Sector III, New Delhi 110017, India

\section{ABSTRACT}

The purpose of this research was to optimize the formulation factors for maximum in vitro permeation of gatifloxacin from aqueous drops through excised goat cornea and to evaluate the permeation characteristics of drug from selected marketed eyedrop formulations. Permeation studies were conducted by putting $1 \mathrm{~mL}$ of formulation on the cornea $\left(0.67 \mathrm{~cm}^{2}\right)$ fixed between the donor and receptor compartments of an all-glass modified Franz diffusion cell and measuring gatifloxacin concentration in the receptor (containing normal saline under stirring) by spectrophotometry at $291.5 \mathrm{~nm}$, after 120 minutes. Raising the drug concentration of the drops increased the drug permeation but decreased the percent permeation and the in vitro ocular availability. Raising the $\mathrm{pH}$ of the formulation from $\mathrm{pH} 5$ to 7.2 increased both the drug permeation and the in vitro ocular availability. Eyedrops containing benzalkonium chloride (BAK; $0.01 \% \mathrm{wt} / \mathrm{vol})$ and disodium edetate (EDTA; $0.01 \% \mathrm{wt} / \mathrm{vol}$ ) showed maximum permeation, followed by Zymar, BAK (0.01\% wt/vol), Gatilox, Gatiquin, and Gate (statistically significant $P<.05$ compared with control). In vitro titration of the formulations with $0.1 \mathrm{~N}$ $\mathrm{NaOH}$ indicated the presence of a buffer in Zymar ( $\mathrm{pH}$ 6) and Gate ( $\mathrm{pH}$ 5.8), which may cause irritation and induce lacrimation, resulting in reduced ocular availability in vivo. Thus, formulation with BAK and EDTA, which is unbuffered, has a better likelihood of being absorbed in vivo. The BAK-EDTA formulation significantly $(P<.05)$ increased the permeation of gatifloxacin through paired excised corneas of goat, sheep, and buffalo, compared with the control formulation. The goat cornea showed the greatest increase in permeation, followed by the sheep and buffalo corneas.

KEYWORDS: gatifloxacin, concentration, $\mathrm{pH}$, preservative, cornea, permeation.

Corresponding Author: Dipak K. Majumdar, Department of Pharmaceutics, Delhi Institute of Pharmaceutical Sciences and Research, formerly College of Pharmacy, University of Delhi, Pushp Vihar, Sector III, New Delhi 110017, India. Tel: +91-11-25847043; E-mail: dkmajumdaar@yahoo.com

\section{INTRODUCTION}

The efficacy of topical therapy with antibacterials (eg, sulfacetamide, chloramphenicol, polymixin B, gentamicin, fluoroquinolones) has been proven for infectious ocular conditions like conjunctivitis, keratitis, and endophthalmitis. ${ }^{1-3}$ Fluoroquinolones, as a group, have shown excellent activity against the most frequently occurring gram-positive and gram-negative ocular pathogens. ${ }^{4-9}$

Fluoroquinolones have a unique mechanism of action: because of their strong affinity to the bacterial enzymes DNA gyrase and topoisomerase IV, they lethally interrupt bacterial replication. There appear to be fewer resistant bacterial strains against fluoroquinolones than against other antibacterials. ${ }^{10}$ Earlier-generation fluoroquinolones such as ciprofloxacin and ofloxacin have been used widely to treat various pathogenic conditions. However, development of resistant strains against these fluoroquinolones has been reported. ${ }^{11,12}$

Gatifloxacin is a fourth-generation fluoroquinolone having a methoxy group in the $\mathrm{C}-8$ position and a piperazine moiety at C-7. Gatifloxacin possesses an improved antibacterial spectrum, particularly against resistant staphylococcus and streptococcus pathogens, compared with older fluoroquinolones. Gatifloxacin has shown good aqueous solubility and better penetration than previous fluoroquinolones, so it has superior efficacy. ${ }^{13,14}$ Studies have shown that topical gatifloxacin solution may be effective in prevention of infectious conditions such as conjunctivitis, keratitis, and postcataract endophthalmitis. ${ }^{15,16}$ Owing to the benefits offered by gatifloxacin, various manufacturers have introduced gatifloxacin eyedrops $(0.3 \% \mathrm{wt} / \mathrm{vol})$. Fluoroquinolones have $\mathrm{pH}$ dependent solubility. ${ }^{17}$ From the comfort and safety point of view, the eye can tolerate a limited range of $\mathrm{pH}$. Preservatives/chelating agents are added to eyedrops primarily to maintain sterility during use. ${ }^{18}$ The available eyedrops are formulated by different manufacturers, so they may vary in the type/concentration of additives and may have varying degrees of permeation through the cornea.

These studies examined the effect of formulation factors (eg, concentration, $\mathrm{pH}$, presence of preservatives) on the corneal transport of gatifloxacin through isolated goat cornea. For the sake of comparison, the permeation characteristics of gatifloxacin from selected marketed formulations 
were evaluated using isolated goat cornea. Attempts were also made to evaluate the permeation characteristics of gatifloxacin from optimized and control formulations through paired corneas of goat, sheep, and buffalo.

\section{MATERIALS AND MeTHODS}

Gatifloxacin sesquihydrate (purity $100 \%$ on an anhydrous basis) was obtained from Ranbaxy Laboratories Ltd (Gurgaon, India) as a gift. Benzalkonium chloride was obtained from Merck (Mumbai, India). The rest of the materials (analytical grade) were obtained from Central Drug House (New Delhi, India). Marketed gatifloxacin eyedrops - Gate (Ajanta Pharmaceuticals Ltd, Mumbai, India), Gatilox (Sun Pharmaceuticals Ind Ltd, Vapi, India), Gatiquin (Cipla Ltd, Verna, India), and Zymar (Allergan [India] Pvt Ltd, Pithampur, India) - were procured from a local market. Fresh eyeballs of goat, sheep, and buffalo were obtained from a local butcher shop (Ambedkar Nagar, New Delhi, India) within 1 hour of the animal's slaughtering. The method of dissection of cornea and the apparatus used in the permeation studies were the same as those described previously. ${ }^{19}$

\section{PERMeATION EXPERIMENT}

Freshly excised goat cornea was fixed between clamped donor and receptor compartments of an all-glass modified Franz diffusion cell in such a way that its epithelial surface faced the donor compartment. The corneal area available for diffusion was $0.67 \mathrm{~cm}^{2}$. The receptor compartment was filled with $10 \mathrm{~mL}$ of freshly prepared normal saline, and all air bubbles were expelled from the compartment. An aliquot $(1 \mathrm{~mL})$ of test solution was placed on the cornea, and the opening of the donor cell was sealed with a glass coverslip, while receptor fluid was kept at $37^{\circ} \mathrm{C}$ with constant stirring using a Teflon-coated magnetic stir bead. The permeation study was continued for 120 minutes; samples were withdrawn from the receptor and analyzed for gatifloxacin content by measuring absorbance at $291.5 \mathrm{~nm}$ in a spectrophotometer (1601 Shimadzu, Kyoto, Japan). Results were expressed as amount permeated and percent permeation or in vitro ocular availability. The permeation (\%) or in vitro ocular availability was calculated as follows:

Permeation $(\%)=\frac{\text { Amount of drug permeated in receptor }}{(\text { Initial amount of drug in donor })} \times 100(1)$

At the end of the experiment, each cornea (freed from adhering sclera) was weighed, soaked in $1 \mathrm{~mL}$ of methanol, dried overnight at $90^{\circ} \mathrm{C}$, and reweighed. From the difference of weights corneal hydration was calculated. The permeation characteristics of gatifloxacin from control and optimized formulations were also evaluated through freshly excised paired goat, sheep, and buffalo corneas. Statistical calculations were done by 1-way analysis of variance followed by Dunnett's test. A paired $t$ test was used for studies with paired corneas. A $P$ value less than .05 was considered significant.

\section{Preparation of Test Solutions}

\section{Gatifloxacin Ophthalmic Solutions of Increasing Concentration of $\mathrm{pH} 7.2$}

The required amount of gatifloxacin was dissolved in a sufficient amount of distilled water, sodium chloride was added to make the final solution isotonic, the $\mathrm{pH}$ of the solution was adjusted to 7.2 using $0.1 \mathrm{~N} \mathrm{NaOH}$ and $0.1 \mathrm{~N} \mathrm{HCl}$, and distilled water was added as needed to bring the final volume up to $100 \mathrm{~mL}$, creating solutions of $0.1 \%, 0.2 \%$, and $0.3 \%(\mathrm{wt} / \mathrm{vol})$ concentration.

\section{Gatifloxacin Ophthalmic Solutions (0.3\% wt/vol) of Different $\mathrm{pH}$}

Gatifloxacin $(0.3 \mathrm{~g})$ was dissolved in a sufficient amount of distilled water, sodium chloride was added to make the final solution isotonic, the $\mathrm{pH}$ of the solution was adjusted to 5.0, $6.0,6.5$, or 7.2 using $0.1 \mathrm{~N} \mathrm{HCl}$ and $0.1 \mathrm{~N} \mathrm{NaOH}$, and distilled water was added as needed to bring the final volume up to $100 \mathrm{~mL}$, creating solutions of different $\mathrm{pH}$.

\section{Gatifloxacin Ophthalmic Solutions (0.3\% wt/vol, pH 6.5) Containing Preservatives}

Gatifloxacin $(0.3 \mathrm{~g})$ was dissolved in a sufficient amount of distilled water, sodium chloride was added to make the final solution isotonic, and the $\mathrm{pH}$ of the solution was adjusted to 6.5. To this solution benzalkonium chloride (BAK; $0.01 \% \mathrm{wt} / \mathrm{vol})$, benzyl alcohol (BA; $0.5 \% \mathrm{vol} / \mathrm{vol})$, thimerosal (THM; $0.005 \% \mathrm{wt} / \mathrm{vol})$, phenyl mercuric acetate (PMA; 0.002\% wt/vol), disodium edetate (EDTA; 0.01\% $\mathrm{wt} / \mathrm{vol})$, or a combination of BAK $(0.01 \% \mathrm{wt} / \mathrm{vol})$ and EDTA $(0.01 \% \mathrm{wt} / \mathrm{vol})$ was added, and distilled water was added as needed to bring the final volume of each solution up to $100 \mathrm{~mL}$.

\section{Surface Tension Measurement}

The surface tension of the following ophthalmic solutions/ marketed eyedrop preparations was measured by using a stalagmometer: (1) gatifloxacin $0.3 \% \mathrm{wt} / \mathrm{vol}$ isotonic solution of $\mathrm{pH} 6.5$; (2) gatifloxacin $0.3 \% \mathrm{wt} / \mathrm{vol}$ isotonic solution of pH 6.5 containing BAK $(0.01 \% \mathrm{wt} / \mathrm{vol})$; (3) gatifloxacin $0.3 \% \mathrm{wt} / \mathrm{vol}$ isotonic solution of $\mathrm{pH} 6.5$ containing $\operatorname{BAK}(0.01 \% \mathrm{wt} / \mathrm{vol})$ and EDTA (0.01\% wt/vol); (4) Gate; (5) Gatilox; (6) Gatiquin; and (7) Zymar. 


\section{In Vitro Titration of Ophthalmic Formulations}

One milliliter of each control formulation, ie control (without additive), optimized (containing BAK and EDTA) and marketed eyedrop, was titrated with $0.1 \mathrm{~N} \mathrm{NaOH}$ to a phenolphthalein endpoint.

\section{RESULTS AND DISCUSSION}

The results of permeation studies through goat cornea (Table 1) showed that an increase in drug concentration in the drops resulted in an increase in amount permeated after 120 minutes, but the percent permeation and in vitro ocular availability decreased. The cornea has 3 layers: the epithelium, the stroma, and the endothelium. Only the amount of drug needed to saturate the epithelium would be able to partition through the stroma and endothelium to the receptor. Thus, an increase in concentration would have a negative effect on the in vitro ocular availability of the drug. Similar findings of reduced in vitro ocular availability with an increase in drug concentration have been reported for ibuprofen, flurbiprofen, ${ }^{20,21}$ and moxifloxacin. ${ }^{22}$ An increase in drug concentration did not affect the corneal hydration, however; it remained in the normal range of $75 \%$ to $80 \% .^{23}$ An increase in moxifloxacin hydrochloride concentration from $0.1 \%$ to $0.3 \%$ (wt/vol) has been found to increase the amount permeated through excised goat cornea by $40 \%$ after 120 minutes, ${ }^{22}$ whereas gatifloxacin showed a more than $100 \%$ increase in permeation under the identical conditions.

An increase in the $\mathrm{pH}$ of the ophthalmic solution from $\mathrm{pH} 5$ to $\mathrm{pH} 7.2$ increased both the amount of drug permeated and the in vitro ocular availability after 120 minutes (Table 1). Gatifloxacin has a $\mathrm{pK}_{\mathrm{a} 1}$ of 5.94 for the carboxyl group and $\mathrm{a} \mathrm{pK}_{\mathrm{a} 2}$ of 9.21 for the piperazinyl group. The drug has a $\mathrm{pI}$ of 7.58. The octanol/water partition coefficient of gatifloxacin at $\mathrm{pH} 5.1$ is 0.044 , whereas at $\mathrm{pH} 7.0$ the value increases to $0.145 .^{24}$ Thus, as the $\mathrm{pH}$ of the formulation is shifted toward neutrality (ie, the $\mathrm{pH}$ of tears), a larger fraction of the drug exists in an un-ionized state that is lipidsoluble. Having a higher lipid solubility at neutral $\mathrm{pH}$ would promote gatifloxacin's permeation through the cornea. Corneal hydration was found to be $83.7 \%$ at $\mathrm{pH} 5$, indicating that a lower formulation $\mathrm{pH}$ is damaging to the cornea. Corneal hydration remained in the normal range when the $\mathrm{pH}$ of the formulation was between 6.5 and 7.2. Transport of moxifloxacin, another fourth-generation fluoroquinolone, across excised goat cornea has also been found to be $\mathrm{pH}$-dependent, with a maximum at $\mathrm{pH} 7.2{ }^{22}$ but the $\mathrm{pH}$-induced increase in permeation was much less marked compared with gatifloxacin's.

Eyedrops are generally dispensed in multidose vials, each of which is intended to be used within a few days, once it is opened. Thus, to maintain the sterility of the preparation during use, a preservative is generally added to the formulation. Some common ophthalmic preservatives in their conventional concentrations were used in making the gatifloxacin $0.3 \% \mathrm{wt} / \mathrm{vol}$ formulation. The $\mathrm{pH}$ of the formulation was kept at 6.5 , in consideration of the better solubility of the drug at lower $\mathrm{pH}$ that will impart physical stability (or prevent crystallization) at low ambient temperature. The effect of preservatives on the transcorneal permeation of the drug was evaluated using excised goat cornea. The results are shown in Table 2 . Formulation with BAK $(0.01 \% \mathrm{wt} / \mathrm{vol})$ showed significantly $(P<.05)$ higher permeation than did the control formulation with no preservative. Formulation with PMA $(0.002 \% \mathrm{wt} / \mathrm{vol})$, THM $(0.005 \% \mathrm{wt} / \mathrm{vol})$, and BA $(0.5 \% \mathrm{vol} / \mathrm{vol})$ produced lower permeation of drug than did the control formulation containing no preservative. EDTA $(0.01 \% \mathrm{wt} / \mathrm{vol})$, a known calcium chelator when used alone, did not increase the permeation of the drug through the cornea. The results are contrary to those observed with moxifloxacin transport through goat cornea. ${ }^{22}$ BAK did not increase the permeation of moxifloxacin, whereas EDTA produced a significant increase in permeation. The physicochemical properties of the drug could affect corneal permeation. The combination of BAK and EDTA (each $0.01 \% \mathrm{wt} / \mathrm{vol}$ ), however, increased the amount permeated and the percent permeation of gatifloxacin the most. Corneal hydration with the formulation containing BAK and

Table 1. Effect of Concentration and $\mathrm{pH}$ on Permeation of Gatifloxacin Through Excised Goat Cornea*

\begin{tabular}{llccc}
\hline \multicolumn{1}{c}{ Formulation Factor } & & $\begin{array}{c}\text { Amount Permeated (mg) } \\
(120 \text { minutes) }\end{array}$ & $\begin{array}{c}\text { Permeation (\%) } \\
(120 \text { minutes) }\end{array}$ & Corneal Hydration (\%) \\
\hline Concentration (wt/vol) (gatifloxacin aqueous & $0.1 \%$ & $0.016 \pm 0.00$ & $1.60 \pm 0.04$ \\
solution of different concentrations at pH 7.2) & $0.2 \%$ & $0.028 \pm 0.001 \dagger$ & $1.40 \pm 0.06$ \\
& $0.3 \%$ & $0.035 \pm 0.002 \dagger$ & $1.17 \pm 0.06$ & $77.9 \pm 0.48$ \\
pH (gatifloxacin 0.3\% wt/vol aqueous & 5.0 & $0.019 \pm 0.00$ & $0.63 \pm 0.03$ & $75.9 \pm 0.65$ \\
solution at different pH) & 6.0 & $0.027 \pm 0.00 \dagger$ & $0.90 \pm 0.03$ & $83.7 \pm 0.35$ \\
& 6.5 & $0.029 \pm 0.00 \dagger$ & $0.97 \pm 0.03$ & $79.1 \pm 0.41$ \\
\hline
\end{tabular}

*Values are mean $\pm \mathrm{SE}$ of 3 corneas in each group. ANOVA indicates analysis of variance.

$\dagger$ Statistically significant $(P<.05)$ compared with solution of $0.1 \%$ concentration as determined by 1 -way ANOVA followed by Dunnett's test. † Statistically significant $(P<.05)$ compared with solution of pH 5.0 as determined by 1 -way ANOVA followed by Dunnett's test. 
AAPS PharmSciTech 2006; 7 (3) Article 57 (http://www.aapspharmscitech.org).

Table 2. Effect of Preservatives on Permeation of Gatifloxacin From 0.3\% Aqueous Solution (pH 6.5) Through Excised Goat Cornea*

\begin{tabular}{lccr}
\hline Preservative & $\begin{array}{c}\text { Amount Permeated (mg) } \\
(120 \text { minutes) }\end{array}$ & $\begin{array}{c}\text { Permeation (\%) } \\
(120 \text { minutes) }\end{array}$ & Corneal Hydration (\%) \\
\hline None (control) & $0.029 \pm 0.00$ & $0.97 \pm 0.03$ & $79.1 \pm 0.41$ \\
PMA & $0.028 \pm 0.00$ & $0.93 \pm 0.02$ & $79.2 \pm 0.23$ \\
THM & $0.025 \pm 0.00$ & $0.83 \pm 0.01$ & $80.6 \pm 0.63$ \\
BAK & $0.071 \pm 0.003 \dagger$ & $2.37 \pm 0.11$ & $77.9 \pm 1.35$ \\
EDTA & $0.027 \pm 0.003$ & $0.90 \pm 0.10$ & $78.7 \pm 0.41$ \\
BAK + EDTA & $0.083 \pm 0.002 \dagger$ & $2.76 \pm 0.08$ & $78.3 \pm 0.81$ \\
BA & $0.026 \pm 0.001$ & $0.86 \pm 0.02$ & $82.1 \pm 0.31$
\end{tabular}

*Values are mean \pm SE of 3 corneas in each group. BAK indicates benzalkonium chloride; EDTA, disodium edetate; BA, benzyl alcohol; THM, thimerosal; PMA, phenyl mercuric acetate.

$\dagger$ Statistically significant $(P<.05)$ compared with control, as determined by 1 -way analysis of variance followed by Dunnett's test.

EDTA was in the normal range $(78.3 \%)$, indicating no corneal damage, while the formulation containing BA showed corneal hydration of $82.1 \%$, indicating slight corneal damage.

The addition of BAK (a cationic surfactant) reduced the surface tension of the gatifloxacin drop from 69.5 to 41.7 dynes $/ \mathrm{cm}$. The addition of EDTA to the formulation marginally reduced the surface tension $(41.2$ dynes $/ \mathrm{cm})$. The relative permeation characteristics of gatifloxacin from the optimized formulation containing BAK and EDTA, as well as from selected marketed preparations, are shown in Table 3 and Figure 1. The optimized formulation showed the highest permeation, followed by Zymar, Gatilox, Gatiquin, and Gate. Gatilox, Gatiquin, and Gate showed significantly $(P<.05)$ higher permeation of drug compared with the control formulation, but their extent of permeation was much less compared with that of the optimized formulation or Zymar. The surface tension of the marketed formulations varied between 34.9 and 40.7 dynes $/ \mathrm{cm}$, indicating the presence of a surfactant. In fact, all the marketed eyedrops contained BAK, which is known to increase the corneal permeation of the drug by disruption of the corneal epithelium. ${ }^{25}$ It can also emulsify the corneal epithelium, leading to increased partitioning of the drug. The lower permeation of drug from Gatilox and Gate appears to be due to the lower $\mathrm{pH}$ of the formulation (pH 5.8), in which most of the drug would remain in the ionized state, while Gatiquin, which had a $\mathrm{pH}$ of 6.7 , should have provided higher permeation, but a low concentration of BAK $(0.005 \% \mathrm{wt} / \mathrm{vol})$ might have contributed to its lower permeation. All 3 formulations showed corneal hydration between $80.6 \%$ and $81.2 \%$, indicating slight corneal damage.

To ascertain the presence of buffer in marketed eyedrop formulations, $1 \mathrm{~mL}$ of each preparation was titrated with $0.1 \mathrm{~N} \mathrm{NaOH}$ to a phenolphthalein endpoint. Zymar had a $\mathrm{pH}$ around 6 , and it consumed $3.35 \mathrm{~mL}$ of $\mathrm{NaOH}$, while the control or formulation with BAK and EDTA consumed $0.05 \mathrm{~mL}$ of alkali. The result suggests the presence of a buffer in Zymar. Similarly, Gate contained a buffer and consumed $3.15 \mathrm{~mL}$ of $\mathrm{NaOH}$. One might like to know the consequences of instilling a buffered drop in a living eye. Studies on ocular drops of pilocarpine, a weakly basic drug $\left(\mathrm{pK}_{\mathrm{a}}=7.1\right)$ used to treat glaucoma, might provide some answers. For maximum chemical stability, pilocarpine (hydrochloride or nitrate) drops are buffered to $\mathrm{pH} 4$ to $5 .^{26}$ Ahmed and Patton ${ }^{27}$ observed a 2-fold higher absorption of pilocarpine from an unbuffered drop of $\mathrm{pH} 4.5$, instilled into rabbit eye, than from a drop buffered with $0.0667 \mathrm{M}$ phosphate buffer of $\mathrm{pH}$ 4.5. A subsequent study by Ahmed and Chaudhuri $^{28}$ also demonstrated higher ocular absorption of pilocarpine from an unbuffered drop of $\mathrm{pH} 4.0$ than from drops of the same $\mathrm{pH}$ containing either $0.0667 \mathrm{M}$ phosphate

Table 3. Relative Permeation Characteristics of Gatifloxacin From Control, Optimized (BAK + EDTA), and Selected Marketed Formulations Through Excised Goat Cornea*

\begin{tabular}{lcccccc}
\hline Formulation & $\mathrm{pH}$ & $\begin{array}{c}\text { Amount Permeated }(\mathrm{mg}) \\
(120 \text { minutes })\end{array}$ & $\begin{array}{c}\text { Permeation (\%) } \\
(120 \text { minutes })\end{array}$ & $\begin{array}{c}\text { Corneal Hydration } \\
(\%)\end{array}$ & $\begin{array}{c}\text { Surface Tension } \\
(\text { dyne } / \mathrm{cm})\end{array}$ & $\begin{array}{c}0.1 \mathrm{~N} \mathrm{NaOH} \\
\text { Consumed }(\mathrm{mL})\end{array}$ \\
\hline Control & 6.5 & $0.029 \pm 0.00$ & $0.97 \pm 0.03$ & $79.1 \pm 0.41$ & 69.5 & 0.05 \\
Optimized & 6.5 & $0.083 \pm 0.002 \dagger$ & $2.76 \pm 0.08$ & $78.3 \pm 0.81$ & 41.2 & 0.05 \\
Gate & 5.8 & $0.037 \pm 0.00 \dagger$ & $1.24 \pm 0.03$ & $80.6 \pm 0.26$ & 35.5 & 3.15 \\
Gatilox & 5.8 & $0.039 \pm 0.00 \dagger$ & $1.30 \pm 0.01$ & $80.9 \pm 0.36$ & 36.5 & 0.15 \\
Gatiquin & 6.7 & $0.039 \pm 0.00 \dagger$ & $1.30 \pm 0.03$ & $81.2 \pm 0.77$ & 40.7 & 0.05 \\
Zymar & 6.0 & $0.076 \pm 0.001 \dagger$ & $2.52 \pm 0.04$ & $71.9 \pm 1.10$ & 34.9 & 3.35 \\
\hline
\end{tabular}

*Values are mean $\pm \mathrm{SE}$ of 3 corneas in each group.

$\dagger$ Statistically significant $(P<.05)$ compared with control as determined by 1 -way analysis of variance followed by Dunnett's test. 


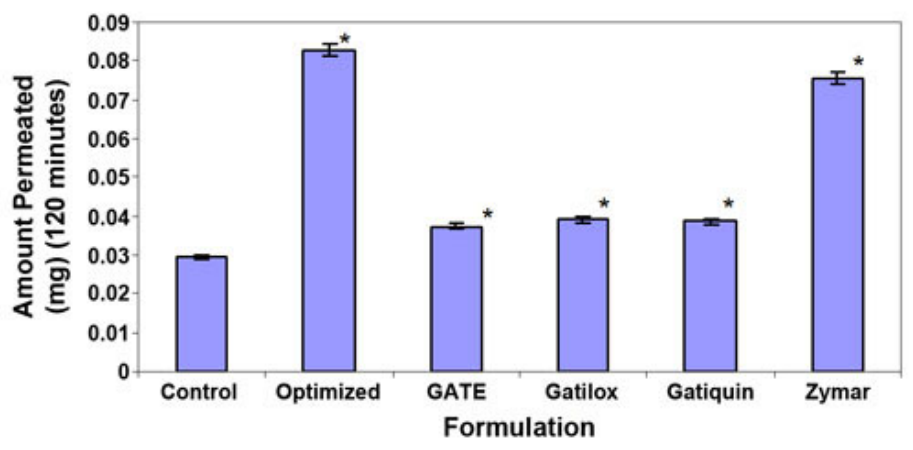

Figure 1. Relative permeation characteristics of gatifloxacin from control, optimized (BAK + EDTA), and selected marketed formulations through excised goat cornea. *Statistically significant $(P<.05)$ compared with control as determined by 1 -way analysis of variance followed by Dunnett's test. BAK indicates benzalkonium chloride; EDTA, disodium edetate.

or citrate or acetate buffer. Buffering a pilocarpine drop below the physiological $\mathrm{pH}$ of tears reduces ocular penetration both by suppressing the absorption of drug (as pilocarpine remains ionized at low $\mathrm{pH}$ ) and by increasing reflex tear production and loss of drug. Zymar or Gate on instillation to the eye would have a similar fate. The presence of buffer would depress the postinstillation $\mathrm{pH}$ of lachrymal fluid, which would then be titrated back to physiological range by tears. Since the formulations have substantial alkali-consuming capacity, on instillation to the eye, they would cause irritation and induce lacrimation, resulting in an influx of tears and an increase in the drainage of the tears containing the drug away from the precorneal area or conjunctival sac. Thus, the formulation with BAK and EDTA, being unbuffered, is likely to be better absorbed than other formulations in vivo, but further studies are needed to confirm this. Zymar showed a corneal hydration of $71.9 \%$, and the formulation appears to be slightly hypertonic.

The permeation characteristics of gatifloxacin from the optimized formulation containing BAK and EDTA and the control formulation were evaluated using paired corneas of goat, sheep, and buffalo. In these paired cornea tests, one

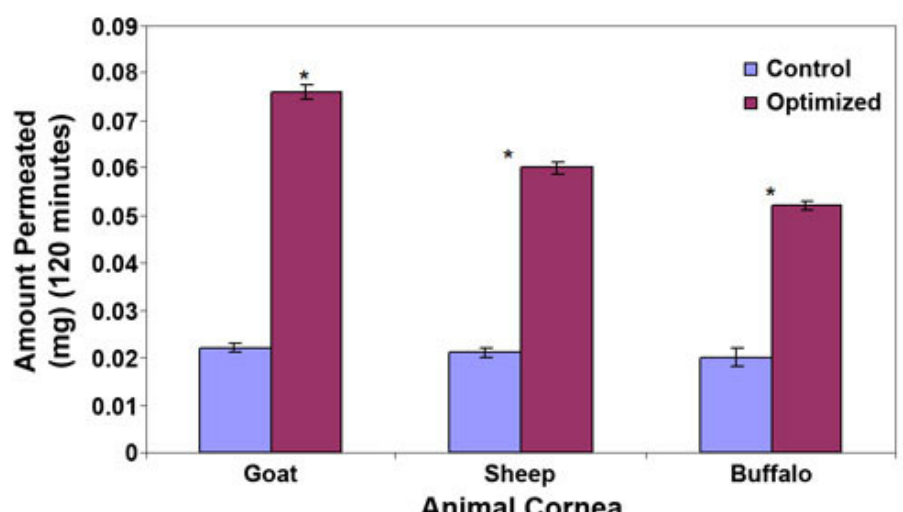

Animal Cornea

Figure 2. Relative permeation characteristics of gatifloxacin from control and optimized (BAK + EDTA) formulations through excised goat, sheep, and buffalo corneas (paired). *Statistically significant $(P<.05)$ compared with control as determined by paired $t$ test. BAK indicates benzalkonium chloride; EDTA, disodium edetate.

cornea from a single animal was treated with the optimized formulation while the same animal's other cornea was treated with the control formulation containing no additive. This procedure was adopted to minimize biological variation. The results (Table 4, Figure 2) showed that, for all the mammalian corneas, the formulation containing BAK and EDTA significantly $(P<.05)$ increased the permeation of gatifloxacin compared with the control formulation. The maximum increase in drug permeation was observed with goat cornea, which had the minimum thickness, and the minimum increase was observed with buffalo cornea, which had the maximum thickness. Corneal hydration levels with sheep and buffalo corneas were in the normal range (ie, $75 \%-80 \%$ ), while with goat cornea the hydration was $80.7 \%$, indicating slight corneal damage. Since the corneal hydration level was below $83 \%$, the damage appears to be reversible. Thus, the optimized formulation could be considered safe and nondamaging to the eye. The combination of BAK and EDTA has also been reported to increase the permeation of moxifloxacin through excised goat, sheep, and buffalo corneas. ${ }^{22}$

Table 4. Relative Permeation Characteristics of Gatifloxacin From Control and Optimized Formulations Through Excised Goat, Sheep, and Buffalo Corneas (Paired)*

\begin{tabular}{|c|c|c|c|c|c|c|c|}
\hline \multirow[b]{2}{*}{ Animal } & \multirow[b]{2}{*}{$\begin{array}{l}\text { Thickness } \\
\text { of the } \\
\text { Cornea (mm) }\end{array}$} & \multicolumn{3}{|c|}{ Control Formulation (No Additive) } & \multicolumn{3}{|c|}{ Optimized Formulation (BAK + EDTA) } \\
\hline & & $\begin{array}{c}\text { Amount } \\
\text { Permeated (mg) } \\
(120 \text { minutes })\end{array}$ & $\begin{array}{c}\text { Permeation }(\%) \\
(120 \text { minutes })\end{array}$ & $\begin{array}{l}\text { Corneal } \\
\text { Hydration } \\
(\%)\end{array}$ & $\begin{array}{c}\text { Amount } \\
\text { Permeated (mg) } \\
(120 \text { minutes })\end{array}$ & $\begin{array}{c}\text { Permeation }(\%) \\
(120 \text { minutes })\end{array}$ & $\begin{array}{c}\text { Corneal } \\
\text { Hydration }(\%)\end{array}$ \\
\hline Goat & $0.66 \pm 0.005$ & $0.022 \pm 0.001$ & $0.73 \pm 0.06$ & $80.2 \pm 0.40$ & $0.076 \pm 0.088 \dagger$ & $2.53 \pm 0.09$ & $80.7 \pm 0.06$ \\
\hline Sheep & $0.80 \pm 0.011$ & $0.021 \pm 0.001$ & $0.70 \pm 0.05$ & $77.3 \pm 0.79$ & $0.060 \pm 0.003 \dagger$ & $2.0 \pm 0.10$ & $77.0 \pm 1.87$ \\
\hline Buffalo & $1.12 \pm 0.011$ & $0.020 \pm 0.002$ & $0.66 \pm 0.06$ & $78.1 \pm 0.31$ & $0.052 \pm 0.004 \dagger$ & $1.73 \pm 0.15$ & $79.1 \pm 0.23$ \\
\hline
\end{tabular}

*Values are mean $\pm \mathrm{SE}$ of 3 corneas in each group.

$\dagger$ Statistically significant $(P<.05)$ compared with control as determined by paired $t$ test. 


\section{AAPS PharmSciTech 2006; 7 (3) Article 57 (http://www.aapspharmscitech.org).}

\section{CONCLUSIONS}

On the basis of these studies, it can be concluded that gatifloxacin $0.3 \%(\mathrm{wt} / \mathrm{vol})$ ophthalmic solution $(\mathrm{pH} 6.5)$ containing BAK $(0.01 \% \mathrm{wt} / \mathrm{vol})$ and EDTA $(0.01 \% \mathrm{wt} / \mathrm{vol})$ provides the maximum in vitro ocular availability through goat cornea. The formulation also increased the permeation of gatifloxacin through excised sheep and buffalo corneas. Among the marketed formulations, Zymar showed the highest permeation, but the low $\mathrm{pH}$ of and presence of buffer in Zymar could increase its ocular irritation potential, which could result in lacrimation and reduced ocular availability in vivo.

\section{ACKNOWLEDGMENT}

The authors are thankful to Ranbaxy Laboratories (Gurgaon, India) for donating the gatifloxacin bulk drug.

\section{REFERENCES}

1. Hardman JG, Limbird LE, eds. Goodman and Gilman's The Pharmacological Basis of Therapeutics. 10th ed. New York, NY: McGraw Hill; 2001.

2. Leeming JP. Treatment of ocular infections with topical antibacterials. Clin Pharmacokinet. 1999;37:351-360.

3. Abshire R, Cockrum P, Crider J, Schlech B. Topical antibacterial therapy for mycobacterial keratitis: potential for surgical prophylaxis and treatment. Clin Ther. 2004;26:191-196.

4. Adenis JP, Colin J, Verin P, Saint-Blancat P, Malet F. Ciprofloxacin ophthalmic solution versus rifamycin ophthalmic solution for the treatment of conjunctivitis and blepharitis. Eur J Ophthalmol. $1995 ; 5: 82-87$.

5. Diamond JP, White L, Leeming JP, Bing Hoh H, Easty DL. Topical $0.3 \%$ ciprofloxacin, norfloxacin, and ofloxacin in treatment of bacterial keratitis: a new method for comparative evaluation of ocular drug penetration. Br J Ophthalmol. 1995;79:606-609.

6. Grosset J. Norfloxacin: a broad-spectrum quinolone for superficial eye infections. Pathol Biol (Paris). 1990;38:735-741.

7. Gross RD, Hoffman RO, Lindsay RN. A comparison of ciprofloxacin and tobramycin in bacterial conjunctivitis in children. Clin Pediatr (Phila). 1997;36:435-444.

8. Jauch A, Fsadni M, Gamba G. Meta-analysis of six clinical phase III studies comparing lomefloxacin $0.3 \%$ eye drops twice daily to five standard antibiotics in patients with acute bacterial conjunctivitis. Graefes Arch Clin Exp Ophthalmol. 1999;237:705-713.

9. Cochereau-Massin I, Bauchet J, Marrakchi-Benjaafar S, et al. Efficacy and ocular penetration of sparfloxacin in experimental streptococcal endophthalmitis. Antimicrob Agents Chemother. 1993;37:633-636.

10. Perry CM, Barman Balfour JA, Lamb HM. Gatifloxacin. Drugs. 1999;58:683-696.

11. Chaudhry NA Jr, Flynn HW Jr, Murray TG Jr, Tabandeh H Jr, Mello MO Jr, Miller D. Emerging ciprofloxacin resistant Pseudomonas aeruginosa. Am J Ophthalmol. 1999;128:509-510.
12. Garg P, Sharma S, Rao GN. Ciprofloxacin resistant Pseudomonas keratitis. Ophthalmology. 1999;106:1319-1323.

13. Perry CM, Ormrod D, Hust M, Susan VO. Gatifloxacin: a review of its use in the management of bacterial infections. Drugs. 2002;62: 169-207.

14. Jensen H, Zerouala C, Carrier M, Short B. Comparison of ophthalmic gatifloxacin $0.3 \%$ and ciprofloxacin $0.3 \%$ in healing of corneal ulcers associated with Pseudomonas aeruginosa-induced ulcerative keratitis in rabbits. J Ocul Pharmacol Ther. 2005;21: 36-43.

15. Kaliamurthy J, Nelson Jesudasan CA, Geraldine P, Parmar P, Kalavathy CM, Thomas PA. Comparison of in vitro susceptibilities of ocular bacterial isolates to gatifloxacin and other topical antibiotics. Ophthalmic Res. 2005;37:117-122.

16. Yee RW, Tepedino M, Bernstein P, Jensen H, Schiffman R, Whitcup SMGatifloxacin BID/QID Study Group. A randomized, investigatormasked clinical trial comparing the efficacy and safety of gatifloxacin $0.3 \%$ administered BID versus QID for the treatment BID versus QID for the treatment of acute bacterial conjunctivitis of acute bacterial conjunctivitis. Curr Med Res Opin. 2005;21:425-431.

17. Ross DL, Riley CM. Aqueous solubilities of some variously substituted quinolone antimicrobials. Int J Pharm. 1990;63:237-250.

18. Hecht G, Roehrs RE, Cooper ER, Hiddemen JW, Van Duzee BF. Design and evaluation of ophthalmic pharmaceutical products. In: Banker GS, Rhodes CT, eds. Modern Pharmaceutics. vol. 40. 2nd ed. New York, NY: Marcel Dekker; 1990:539-603.

19. Malhotra M, Majumdar DK. In vitro transcorneal permeation of ketorolac tromethamine from buffered and unbuffered aqueous ocular drops. Indian J Exp Biol. 1997;35:941-947.

20. Gupta M, Majumdar DK. Effect of concentration, $\mathrm{pH}$ and preservative on in vitro transcorneal permeation of ibuprofen and flurbiprofen from non-buffered aqueous drops. Indian J Exp Biol. 1997;35:844-849.

21. Richman JB, Tang-Liu DD. A corneal perfusion device for estimating ocular bioavailability in vitro. J Pharm Sci. 1990;79: 153-157.

22. Pawar PK, Majumdar DK. Effect of formulation factors on in vitro permeation of moxifloxacin from aqueous drops through excised goat, sheep, and buffalo corneas. AAPS PharmSciTech. 2006;7:E13.

23. Maurice DM, Riley MV. Ocular pharmacokinetics. In: Graymore CN, ed. Biochemistry of the Eye. London, UK: Academic Press; 1970: 6-16.

24. Bristol Myers Squibb Company. New Drug Application for Tequin (Gatifloxacin Tablets and Injections). Environmental Assessment. Center for Drug Evaluation and Research Website. 2001.

Accessed: May 31, 2006.

25. Fu RC, Lidgate DM. In vitro rabbit corneal permeability study of ketorolac tromethamine. Drug Dev Ind Pharm. 1986;12:2403-2430.

26. Gibaldi M. Biopharmaceutics and Clinical Pharmacokinetics. Philadelphia, PA: Lea \& Febiger; 1984.

27. Ahmed I, Patton TF. Effect of $\mathrm{pH}$ and buffer on the precorneal disposition and ocular penetration of pilocarpine in rabbits. Int J Pharm. 1984;19:215-227.

28. Ahmed I, Chaudhuri B. Evaluation of buffer system in ophthalmic product development. Int J Pharm. 1988;44:97-105. 